\title{
Pedagogical Implications on Medical Students' Linguistic Needs
}

\author{
Yanling Hwang \\ E-mail: yanling_h@yahoo.com
}

\author{
Received: March 28, 2011 \\ Accepted: July 11, 2011 \\ Published: December 1, 2011 \\ doi:10.5539/elt.v4n4p138 \\ URL: http://dx.doi.org/10.5539/elt.v4n4p138
}

\begin{abstract}
In this paper, an extended teaching implication is performed based on the study of medical students' linguistic needs in Tawian (Hwang, Lin, 2010). The aims of previous study were to provide a description of the linguistic needs and perceptions of medical students and faculty members in Taiwan. However, this paper put more thoughts on the pedagogical application of the findings. The paper presented teaching implication of medical English or general English based on perceptions of medical students and faculty members. The extended study related to the teaching application tended to answer the following six issues: (1) the use of the English language (2) the importance of using English in the medical field (3) evaluations of medical students' English ability (4) a needs analysis of the English course for the School of Medicine (5) suggestions about the English curriculum for the School of Medicine and (6) other assistance or requirements identified by students.
\end{abstract}

Keywords: Pedagogical implications, English teaching, Linguistic needs, Medical field

\section{Introduction}

English teaching in the $21^{\text {st }}$ Century has been undergoing major changes. Teaching English in an area with a specific expertise turns into the mainstream such as English for tourism, English for business, and English for medical purposes. Particularly, English is motivated to be a primary language course to be taught at medical schools due to a rapid change in the global working environment and encouraged by a genuine need of the promotion of practical research on medical fields. English proficiency is a compulsory fundamental for medical students who wish to practice medicine in this global working environment in Taiwan. Moreover, English is also a communicative mean to conduct research on the medical filed. Most disciplines within medicine take place in a professional society or an association with meetings and publications in relation to English. With this regard, the level of English proficiency of medical professionals will be attributed to the quality of medical profession and research.

Hwang and Lin (2010) investigated the medical students' linguistic needs in Taiwan and explored the perceptions of English needs. By assessing both the medical students' and faculty members' English needs, this study tried to satisfy the needs of both, and to facilitate their medical English language learning. Particularly, the results of the teacher and student surveys were integrated and presented according to the following six issues: (1) frequency of the use of English by medical students, (2) importance of using English in the medical field, (3) evaluations of medical students' proficiency in English, (4) needs analysis of the English course for the School of Medicine, (5) suggestions for improving the English curriculum for the School of Medicine, and (6) other assistance or requirements for medical students' linguistic needs. The previous study was limited to exploring and revealing the perceptions of medical students and faculty on medical students' linguistic needs in Taiwan; however, the weigh of detailed and thorough teaching implications and pedagogy on English for Specific Purpose (ESP) was insufficient. In this paper, the brief summary of the previous study and further insights on its teaching application were explored.

\section{Theoretical Discussion}

\subsection{Needs analysis}

Given that an ESP course employs a learner-centered approach that attempts to meet learners' particular language needs, the teacher must undertake a needs analysis before proceeding. This analysis of student needs has been regarded as a necessity by those involved in language curriculum reform from as far back as the 1970s (Berwick, 1989). Needs analysis, by definition "...contrasts with the assumption underlying many methods, namely, that the needs and goals of learners are identical, that what they need is simply 'language,' and that Method X is the best way to teach it" (Richards \& Rogers, 1992, p.156).

Needs analysis has generally accepted characteristics according to researchers who have studied English language education. First, Van Ek (1987) emphasized that language learning objectives must correspond to learners' needs. Any needs analysis must consider three elements: (1) the target group (2) their needs and (3) the situations in which 
they will use the foreign language. Robinson (1991) suggested that there are several target groups: (1) potential students (2) teachers and administrators (3) people who were or would be involved in the learners' study or specific job and (4) past students.

Needs analysis is usually considered to be the foundation of the ESP process, so it must be conducted before the course is designed. Hutchinson and Waters (2001) noted that the purpose of an ESP course is to enable learners to function adequately in a target situation in which the learners will use the language they are learning. Therefore, as mentioned earlier, the ESP course design process should be preceded by an assessment of the target situation and a rigorous analysis of its linguistic features. The identified features will be the targets of the syllabus used in the ESP course.

According to Gardner and Winslow (1983), a main purpose of conducting a needs analysis is to produce information which when acted upon makes courses better adapted to students' needs. They also stated that "...a part of the objectives of formal needs identification is to back up one's proposals with quantitative evidence of their importance." (p.76). They added, "[I]n many cases, concrete evidence of particular needs, such as these surveys produced, could be directly used as part of the course validation / approval procedure" (p.76).

According to Dudley-Evans and St John (1998), "Initially obtained data on needs analysis allow researchers to set course objectives and determine a scientific approach to teaching. Ongoing needs analysis allows teachers to revise objectives and to modify teaching techniques and materials. In ongoing needs analysis the conclusions drawn in the initial analysis have to be constantly checked and re-assessed. In addition, the researchers said that a needs analysis must be "...interrelated with course design, materials, teaching/learning, assessment / evaluation" and be on-going (p.121). They concluded that a needs analysis is the first important stage in an ESP course, and that is an on-going process of "...establishing the what and how of a course" (p.121).

\subsection{English for medical purposes (EMP)}

Lee (1998) defined EMP as a specialized English course for students or for those working in nursing and medical areas. EMP may include job-related English skills such as medical terminology, abbreviations and conversations used in performing daily medical tasks.

EMP is a form of English as a Second Language education that clearly emphasizes medical English according to the needs of one's job such as writing progress notes and charting, interviewing and assessing patients and reporting.

\subsection{Studies related to English for medical purposes}

There have been a number of studies on EMP within the field of ESP. These studies have addressed the English needs of medical students in China (Xu \& Xiao, 2006; Zhuo, 1989), language problems of international medical doctors who work in American hospitals (Cameron \& Williams, 1997), the relationship between a non-native English-speaking physician's pronunciation and a nurse's perception of his medical competency (Horani, 1995), the teacher's role in an EMP course (Chang, 2007), and English needs of medical school students in Taiwan (Chia, 1999; Fang, 1987; Shen, 1996). Some ESP researchers have targeted the field of science, technology, and business (Kuo, 1987). Only a few have considered ESP in the field of medicine.

Chang (2007) stated "We noticed that attention to learners' needs is a key element in any definition of ESP. Therefore, EMP is intended to help a medical student who is planning to study medicine in English. It is assumed that this medical student will have some knowledge of general English but limited experience of studying works in medical English" (p.2).

In order to investigate the English needs of medical school students in Taiwan, Fang (1987) surveyed university students in various medical-related departments, including medicine, dentistry, pharmacy, nursing, and medical technology, to uncover their learning attitudes and English learning needs. She claimed that students realized the importance of English competence for success in their studies and future careers. The results showed that most of the students said that their main reason for learning English was to acquire professional knowledge. Their ranking of English needs was, from the highest to the lowest, self-actualization, communicative competence, and linguistic competence. The students ranked the four types of freshman English courses, from the most needed to the least as EGP, specialized English, academic English, and English literature. They regarded listening skills as the most important and writing skills as the least important. Although students were strongly motivated to improve their English skills, English education in colleges and universities did not meet their expectations and did not nurture their language competency.

Shen (1996) conducted research concerning the English needs of Taiwanese medical students and medical practitioners in order to differentiate them. The study found that both medical students and medical doctors realized the importance of English and had a strong incentive to learn medical English. Nevertheless, the English needs of 
medical students were academic-related, while professionals' English needs were work-related. The implication was that English was much more important to those employed in a medical field, and medical students needed to be more proficient in English in order to meet future job requirements.

Chia (1999) carried out an English needs analysis on 349 college students and 20 faculty members at Chung Shan Medical School in Taiwan and reported that both medical students and their instructors agreed about the importance of English. Both groups ranked reading as the most important skill, followed by listening, writing and speaking. It is noteworthy that freshmen did not think their listening skills needed to be improved and said that writing was the skill least needed. As for listening, medical students all felt that improving the ability to understand daily conversations was most important for incoming freshmen. Chia also found that the majority of the students selected reading English language newspapers and magazines, participating in daily conversations in English, and writing reports and research papers in English as being important (p.112). According to Chia, "Regarding English language problems of students as perceived by faculty and students, limited vocabulary, slow reading speed, and poor listening comprehension were rated highest. Poor grammar was rated the lowest" (p.113). As to the design of English curricula, most of the students preferred that General English be taken in the freshman year, followed by elective EMP courses in the ensuing years.

\subsection{Cooperative learning}

The use of effective and active learning strategies, such as cooperative learning (CL), has recently drawn the attention of second language teachers. In addition, cooperative learning technique plays an important role in the student-centered approach. Hwang and Huang (2007) provided a definition, discussed the role CL plays in L2 learning, and considered the assessment of students' achievements.

Cooperative learning (CL) is defined as the principles and strategies for enhancing the value of student-student interaction. Collaborative learning is grounded in the philosophy of constructivism. In a constructive theory, learners mostly take in control of their learning process, tasks, and problems. Students work through the assignment until all group members successfully understand and complete it. Rewards for the individual students within the group are generally based on the accomplishment of the group as a whole. The purpose of CL is to build individual and group responsibility for learning and to build success for all members of the group. In other words, the concept of CL is similar to the concept of the Zone of Proximal Development (ZPD) by in terms of socialcultural perspective of development. He claims that each participant can potentially act in some ways that assist the others, and all can learn from the other's contribution. The role of social interaction is defined in creating an environment to learn language, learn about language, and learn through language. (Yang \& Chen, 2007).

\section{The Summary of the Previous Study}

The study of Hwang and Lin (2010) was designed to assess medical students' English needs in Taiwan. The participants were 378 medical students in the Department of Medicine at Chung Shan Medical University, including 117 freshmen, 79 sophomores, 59 juniors, 79 seniors, 44 fifth-year medical student, and 24 faculty members. There were $67.7 \%$ male and $32.3 \%$ female. Of the total number of 24 teacher participants, $82.6 \%$ were male, while only $17.4 \%$ were female. The participants were divided into groups. (see Table 1)

The research was designed to answer the following questions:

1. To what extent do medical students / faculty use English as a medium?

2. How do medical students / faculty rate their own competence with regard to particular skills in English language aspects?

3. How do medical students / faculty evaluate their current English ability?

4 What are the medical students' / faculty's perceptions of their language needs?

5. What are medical students' perceptions of their English learning styles and their expectations of teachers?

6. What other assistance regarding English should be provided to medical students?

The questionnaire consisted of seven sections of 30 questions, which were parallel to those in the version given to the students. Chi-square and one-way ANOVA analyses were also conducted in order to determine the perceptions of English language needs of medical students, and to compare the perceptions held by the three groups: faculty (F), lower-class group (LC) and upper-class group (UC).

\section{Discussion and Pedagogical Implications of English Linguistic Needs among Medical Students}

\subsection{Use of the English language as a medium}

Almost all of the teachers indicated that they lectured in Chinese, using English only for medical terms. Based on 
the responses of the faculty to the questionnaires, almost $80 \%$ of the faculty members reported that over $50 \%$ of the reading materials, such as textbooks or journal articles that they gave students, were written in English, whereas over half of the students stated that less than $50 \%$ of the reading materials were in English. A possible reason for this discrepancy is that students might use both the English and Chinese versions of the textbooks.

With regard to the use of English in class, students (LC \& UC) and faculty were in agreement that examination answers were done in English (48.5\%) and that reports were written in English (43.3\%). Surprisingly, compared to other items, a number of participants (14.7\%) thought that there were no circumstances in which medical students need to use English as a medium of communication. Probably this is consistent with the fact that lecturing is in Chinese. However, the teachers gave medical terms in English. Based on further interviews with the participants, not only the students but also the faculty members maintained that it is still much easier for medical students to understand the medical knowledge in Chinese rather than in English.

As a result, the faculty members either delivered their lectures in Chinese or asked the medical students to use Chinese as a medium to express their understanding of medical knowledge. Another possible reason is that the faculty members who participated are the teachers who usually teach the medical students during their first and second years at the university. These students have not yet taken the core medical curriculum and are undertaking the preparation courses, which are content courses.

\subsection{Importance of using English}

Generally speaking, medical students said that English was very important in their current studies and with regard to their future careers. This finding is identical with those of Chia,(1999), Fang (1987) and Tsai (2001). Nevertheless, in comparison to the faculty members, the findings illustrated that the latter perceived English to be more important than did the students. However, students were aware of the importance of English, and these findings agree with those of Chia (1999). As for the language skills, both the students and teachers regarded reading as the most important, followed by listening, speaking, and writing.

\subsection{Evaluations of medical students' English ability}

With regard to the examination of English language problems that students are currently facing in their academic studies, poor speaking skills, limited vocabulary, and poor listening comprehension were rated as the main problems. Poor reading comprehension was rated as the easiest problem to solve, which is not in accord with the findings of Guo (1987) and Chia (1999).

Both students and faculty members considered reading and understanding English textbooks and medical journal articles as an important English skill for success in medical studies, which matches the findings of Chia (1999). Interestingly, faculty members rated writing research papers as next most important. The implication is that medical teachers need to write medical research papers in English, and this has an effect on their promotion prospects.

\subsection{Needs analysis of the English course for the School of Medicine}

Students and faculty members were in agreement that the materials in the English course should be relevant to the medical field. The responses among the three groups were not significantly different $(\mathrm{p}>0.05)$.

When participants were asked to choose the focus of the language skill of English materials related to the medical field in an English course, $51.7 \%$ of the respondents indicated that the materials in the English course should be relevant to medical reading, which echoes the findings of Chia (1999). Specifically, a majority of the senior and fifth-year medical students and the faculty members believed that reading English medical journals should be the focus of the reading course. Evidently, their purpose is research-oriented. Moreover, the senior and the fifth-year medical students and the faculty members thought that writing medical reports should be the focus in terms of writing. It is noteworthy that both the UC (47.7\%) and F (52.2\%) selected the aspect that has a research-oriented purpose.

Based on the responses of students and faculty, the best pattern of curriculum design for English courses was general English in the freshman year, followed by medical English in the second and third years. This finding is congruent with the previous finding that materials in an English course should be relevant to the medical field, and probably points out that medical students feel that medical English is very important.

Furthermore, a majority of the students and faculty agreed on the focus of course curricula: freshmen should take a reading class, sophomores enroll in a listening class, and juniors focus on a conversation class. The implication is that the medical students want to focus on the input of English language learning (reading and listening) before concentrating on the output of English language learning (speaking and writing). 


\subsection{Suggestions related to the English curriculum for the School of Medicine}

The majority of respondents indicated that learning individually and learning in small groups in an English course, would help them more with their English language skills than learning with the whole class. Probably this is because the size of the classes is usually too big (65 students), and the students wanted more individual attention from the teachers. In addition, $63.3 \%$ of the students declared that they found singing songs and $42.4 \%$ of the students indicated that talking with students and listening to others helped them learn English. Several pedagogical implications can be drawn from these findings that are in accord with the basic characteristics of CLT proposed by Nunan (1991).

A majority of the students (66.1\%) maintained that they got a sense of satisfaction from feeling more confident in situations that they had found difficult in a previous English course, while $44.7 \%$ of the students believed that they got a sense of satisfaction from passing a certain English proficiency exam (such as, TOEFL, TOEIC, and GEPT). This finding supports another finding that additional requirements should be added (such as having a score higher than 80 on the TOEFL iBT test, 750 on the TOEIC test or taking extra English courses) to help the medical students improve their English proficiency.

\subsection{Other assistance or requirements related to English}

Finally, regarding the policy of lecturing in English, over $60 \%$ of the participants believed that it would be helpful. Similarly, most of the participants considered the policy requiring them to learn the English language should also have a positive effect on the improvement of their English ability. However, there were significant differences among the three groups $(\mathrm{p}<0.01)$. In comparison to the students, the findings showed that faculty members perceived English to be more important. Nevertheless, students were aware of the importance of English, and these findings are in line with the study done by Chia (1999).

\section{Conclusion \& Suggestions}

\subsection{Pedagogical implications}

Based on the findings of this study, I will propose some suggestions related to the ESP teaching methods, course and curriculum construction, and the role of the ESP teacher in the Medical School. I hope they provide some ideas for English teachers or school administrators as a means of improving the English curricula they offer and the teaching of ESP to students in the medical field.

First, the research demonstrates that a communicative language teaching (CLT) method can be applied to ESP teaching. Su (2001) suggested that the English curriculum should integrate ESP teaching and general English teaching. English teaching methodology has gradually changed from the traditional grammar-translation method to the CLT method that emphasizes a student-centered approach in the English classroom setting. A student-centered approach is considered to be the cornerstone of successful learning. A current trend in teaching is to take into account what learners want, since they will have to carry out a variety of communicative tasks in the target language. Experts recommend that cooperative learning techniques be used as part of a student-centered approach. In terms of assessing the outcomes of a cooperative learning group, students should be responsible for learning the assigned material, solving problems, contributing to the assigned project, making sure that all other group members learn the assigned material, and making sure that all other class members successfully learn the assigned material. They are learning by doing. The cooperative learning approach aims to increase student-to-student interaction and enhance students' interest in learning the language. The student-focused curriculum, which improves student motivation and the chances of student success, focuses on the learning needs and future goals of the student. It provides a format for the curriculum and forms the foundation of post-modern curriculum design (Knowles, 1980).

Secondly, in line with the study done by Su (2001), the general English curriculum should cultivate and emphasize listening, speaking, and reading skills. Authentic reading materials, such as English language newspapers and magazines, should be used so that students will not be able to find translations. Group discussion, cooperative learning, role-playing, and problem solving can be used in the English classroom to improve students' listening and speaking abilities. Students should be managers of their own learning, and they should be encouraged to negotiate meaning, interact with others in the group, and use effective and active learning strategies that will reinforce the value of student-to-student interaction. Moreover, up-to-date information and authentic audio-visual materials, such as sit-coms from TV, songs or clips from YouTube, or DVDs, create an authentic English learning environment so that students will be immersed in the use of English.

Third, Hutchinson and Waters (2001) noted that the purpose of an ESP course is to enable learners to function adequately in a target situation in which they will use the language they are learning. If the purpose of learning the language is to communicate with, and provide medical services for English speaking patients, and to write papers, 
adequate training classes to meet such needs should serve the purpose. Therefore, it is advised that EGP courses ought to be offered in the freshman year, and EMP courses designed for seniors, as many researchers have proposed (Chia et al., 1999; Fang, 1987; Shen 1996). Shieh and Wu (1988) found that more than half of the freshmen at National Tsinghua University preferred to have general English courses in their freshman year. This suggested that ESP lessons should be conducted in the later stages of a students' professional training. ESP is generally designed for intermediate or advanced students.

Responding to questions about curriculum design, the majority of the students and faculty thought that freshmen should be enrolled in a reading class, sophomores in a listening class, and juniors in a conversation class. Students who have developed basic knowledge and language skills in an EGP course at the beginning of their medical studies are able to acquire general linguistic competence. Once they have obtained good general English skills, students will be able to master English skills needed in a specialized field in order to access professional communicative skills.

\subsection{The teacher's role in English for special purposes}

This study addressed the English linguistic needs of medical professionals in Taiwan and provided an overview of the current English courses designed to meet the needs of students at medical universities. Teachers of ESP intend to prepare students meeting the real-world demands, delivering pragmatic, experience-based instruction.

An experienced EFL teacher can exploit his/her professional experience and background in ESP teaching. If he or she has some knowledge of the special subject matter, he/she can choose appropriate learning materials that meet the needs of medical students. An ESP teacher should perform as the organizer, course manager, monitor, adviser, or facilitator.

The ESP practitioner is also the course planner and materials provider. Furthermore, Gatehouse (2001) claimed that the approach of meeting learner needs has to do with the ways in which learners acquire language, and the differences in the ways language is acquired. Syllabus design plays an important role in any level of curriculum. Paltridge (2003) proposes three key developments in teaching: needs-based programming teaching, competency-based language teaching, and genre-based language teaching. In other words, teachers should analyze the needs of their learners and negotiate language learning objects with them at the beginning of the course. According to the needs analysis, the teaching materials and activities provided in class are appropriate to professional and career-related syntax, vocabulary, and discourse that learners need in order to participate, particularly in spoken and written genres. Then, learning outcomes should be introduced in terms of performance assessment, and what a learner can master by the end of a course.

To balance these roles, ESP teachers need to possess a great deal of flexibility and be interested in the disciplines or professional activities in which the students are involved. Moreover, teachers should be willing to be challenged and be armed with a sound knowledge of both theoretical and practical developments to empower them to make good decisions that lead to the successful contribution of ESP education for medical students.

\section{References}

Bay, D. (1994). Instrumentality and Integration: A Taxonomic Approach to Analyzing Motivational Factors in Syllabus and Materials Design for English for Nursing Purposes in Japan. Annual of Keio Junior College of Nursing, 4, 25-32

Berwick, R. (1989). Needs assessment in language programming: From theory to practice. In R. K. ohnson (Ed.), The Second Language Curriculum. Cambridge: Cambridge University Press. pp. 48-62

Cameron, R., \& Williams, J. (1997). Sentence to ten cents: A case study of relevance and communicative success in nonnative-native speaker interactions in a medical setting. Applied Linguistics, 18(4), 415-445. http://dx.doi.org/10.1093/applin/18.4.415

Chang, J. P. (2007). Teacher's role in teaching English for medical purposes (EMP). Sino-US English Teaching, 4(7), $1-8$

Chia, H. U., Johnson, R., Chia, H. L., \& Olive, F. (1999). English for college students in Taiwan: A study of perceptions of English needs in a medical context. English for Specific Purposes, 18(2), 107-119. http://dx.doi.org/10.1016/S0889-4906(97)00052-5

Dudley-Evans, T., \& St John, M. J. (1998). Developments in English for specific purposes. Cambridge: Cambridge University Press.

Fang, F. S. (1987). An evaluation of the English language curriculum for medical students. Papers from the Fourth Conference on English Teaching and Learning in the Republic of China. Taipei: Crane Publishing Co. pp. 111-129 
Gardner, P. H., \& Winslow, J. D. (1983). Present and proposed methods of determining the needs of students in public sector identifying language needs. Pergamon Press.

Gatehouse, K. (2001). Key issues in English for specific purposes (ESP) curriculum development. The Internet TESL Journal, 7

Guo, C. (1987, May). A needs study of undergraduate and graduate EST students and in-service technical professionals. Paper presented at the fourth conference on English teaching and learning in the Republic of China, China.

Horani, L. A. (1995). The effect of a physician's pronunciation on nurses' perceptions of the physician's medical competency. Unpublished master's thesis. Portland State University, Oregon, USA.

Hutchinson, T., \& Waters, A. (2001). English for specific purposes. Cambridge: Cambridge University Press.

Hwang, Y. L., \& Huang, P. W. (2007). Learning together. English Teaching Professional, 53, 28-29

Hwang, Y. L., \& Lin, S. (2010). A study of medical students' linguistic needs in Taiwan. The Asian ESP Journal, $6(1), 35-58$

Knowles, M. S. (1980). The modern practice of adult education: Andragogy versus pedagogy. Prentice Hall/Cambridge, Englewood Cliffs.

Kuo, C. H. (1987). An EST needs study on college and graduate students and in-service professionals. Proceedings of the Fourth Conference on English Teaching and Learning in the Republic of China. Taipei: Crane Publishing Company. pp. 263-273

Lee, C. Y. (1998). English for Nursing Purposes: A Needs Assessment for Professional-Oriented Curriculum Design. The Proceedings of the Seventh International Symposium on English Teaching. Taipei: The Crane Publishing Co., LTD. pp. 615-625

Nunan, D. (1991). Communicative tasks and the language curriculum. TESOL-Quarterly, 25(2), 279

Paltridge, B. (2003). Underlying philosophies of English language education in Australia. English Teaching, 58(1), $273-284$

Richards, J. C., \& Rogers, T. S. (1992). Approaches and method in language teaching. Cambridge: Cambridge University Press.

Shen, Y. M. (1996). Discussion and comparison of differences of learning medical English between medical professionals and medical students. Papers from the Fourth Conference on English Teaching and Learning in the Republic of China. Taipei: Crane Publishing Co. pp. 31-40

Shieh, Y. L., \& Wu, Y. S. (1988). A needs analysis for the curriculum and syllabus of Freshman English at Tsinghua University. In Proceeding of the Second Conference on English Teaching and Learning in the Republic of China. Taipei: Crane Publishing Co. pp.82-97

Su, S. W. (2001). A study of English curriculum in junior colleges: the perception of junior college graduates. Bulletin of Yang-Ta Institute of Technology and Commerce, 2(2), 35-46

Tsai, P. H. (2001). An Assessment of English Needs of Nursing Students and Professionals. Selected Papers from the Tenth International Symposium on English Teaching. Taipei: The Crane Publishing Co., LTD. pp. 608-620

Van Naerssen, M. M. (1978). ESL in medicine: A matter of life and death. TESOL Quarterly, 12(2), 193-203. http://dx.doi.org/10.2307/3585609

Vygotsky, S. L. (1987). Thinking and speech. In R.W. Riber \& A.S. Carton (eds.), The collected works of S.L. Vygotsky, Volume 1, Problems of general psychology. New York: Plenum.

Xu, J., \& Xiao, X. Y. (2006). Need analysis of medical postgraduates' English language learning. China Higher Medical Education, 7, 33-34

Yang, S. C., \& Chen, Y. J. (2007). Technology-enhanced language learning: A case study. Computers in Human Behavior, 23(1), 860-879. http://dx.doi.org/10.1016/j.chb.2006.02.015

Zhuo, X. M. (1989). English curriculum for medical students in the People's Republic of China. Doctoral dissertation. University of Massachusetts Amherst, ProQuest. 
Table 1. Descriptive Statistics on the Participants

\begin{tabular}{|c|c|c|c|c|}
\hline Group & status & $\underline{\mathrm{n}}$ & male & female \\
\hline \multicolumn{5}{|l|}{ LC } \\
\hline & freshman & 117 & & \\
\hline & sophomore & 79 & & \\
\hline & junior & 59 & & \\
\hline \multicolumn{5}{|l|}{$\mathrm{UC}$} \\
\hline & senior & 79 & & \\
\hline & fifth-year & 44 & $67.7 \%$ & $32.3 \%$ \\
\hline & & 378 & & \\
\hline $\mathrm{F}$ & faculty & 24 & $82.6 \%$ & $17.4 \%$ \\
\hline Total & & 402 & & \\
\hline \multicolumn{5}{|c|}{ Note: LC: Lower Class } \\
\hline \multicolumn{5}{|c|}{ UC: Upper Class } \\
\hline & & & & \\
\hline
\end{tabular}

